\title{
CONTRIBUCIÓN DEL CÓMIC \\ A LA IMAGEN DE LA CIENCIA
}

Daniel Gil Pérez, Jaime Carrascosa Alís,
Adriana Patricia Gallego e Isabel Fernández
las Ciencias. Universitat de València. España.

Departamento de Didáctica de las Ciencias. Universitat de València. España.

\begin{abstract}
This paper will be devoted to the critical analysis of series of simple concepts on science and scientific work as it is presented by comics now available at the market place (so far as they refer to a scientific theme).
\end{abstract}

\section{RESUMEN}

En este trabajo nos centramos en el análisis crítico de toda una serie de concepciones simplistas acerca de la ciencia y del trabajo científico transmitidas por los cómics existentes en el mercado (en la medida que hagan referencia la trabajo científico).

\section{PLANTEAMIENTO DEL PROBLEMA}

Existe un consenso muy generalizado en que la educación científica constituye un elemento esencial de la cultura de nuestro tiempo. Más aún, la necesidad de una alfabetización científico tecnológica de todos los ciudadanos y ciudadanas se ha abierto paso con fuerza en estos últimos años, hasta llegar a convertirse en una exigencia urgente. Así, por ejemplo, lo ha entendido la administración USA, que ha convertido el esfuerzo en educación en su primera prioridad, y así se afirma, desde la primera página, en los National Science Standards, auspiciados por el National Research Council (1996): "La alfabetización científica es una meta explícita a conseguir" y agrega "En un mundo repleto de productos resultantes de la indagación científica, la educación científica se ha convertido en una necesidad para todos".

Junto a esa creciente importancia concedida a la educación científica, nos encontramos, sin embargo, con un grave fracaso escolar, acompañado de una imagen deformada de la ciencia y de actitudes negativas hacia la ciencia y su aprendizaje (Simpson et al 1994; Hodson 1994). Estos decepcionantes resultados, que afectan tanto a la enseñanza secundaria como a la universitaria, se han convertido en un motivo de seria preocupación que no puede despacharse con explicaciones simplistas (basadas, por 
ejemplo, en una supuesta "incapacidad" para las ciencias de la mayoría de los estudiantes) sino que ponen en evidencia graves deficiencias de la enseñanza (Yager y Penick 1983; Porlán y Martín 1994).

A este respecto, comienza a comprenderse que, si se quiere cambiar lo que los profesores y los alumnos hacemos en las clases de ciencias, es preciso previamente modificar la epistemología espontánea de ambos colectivos (Bell y Pearson 1992; Désautels et al 1993). Con otras palabras: el cambio de las ideas simplistas y deformadas sobre la ciencia y el aprendizaje científico aparece como una condición necesaria -aunque no suficiente (Hodson 1993) - para poder llevar a cabo planteamientos innovadores, porque dichas ideas simplistas tienen implicaciones en muchos aspectos que resultan claves para la enseñanza y el aprendizaje de las ciencias como, por ejemplo, los trabajos prácticos, la resolución de problemas, la introducción de conceptos, la evaluación, etc. (Guilbert y Meloche 1993; Meichtry 1993).

Nuestro estudio parte, precisamente, de la intuición básica de que el cómic podría constituir un instrumento especialmente indicado para, en primer lugar, estudiar la imagen de la ciencia que se forma en los estudiantes. Una cuidadosa revisión bibliográfica nos ha permitido constatar que esta utilización de los cómics cuenta ya con una cierta tradición, tanto en lo que se refiere al estudio de la imagen de la ciencia que éstos suelen transmitir (Bassalla 1976; McAdam 1990), como a su uso para detectar las concepciones simplistas que muchos estudiantes e incluso profesores tienen al respecto (Chambers 1983; Schibeci 1986).

Sin embargo, una gran parte de los estudios que hasta recientemente se han realizado en este campo, se han centrado principalmente en la crítica a concepciones de tipo empirista, olvidando otras deformaciones a nuestro entender tanto o más graves. Pensamos, pues, que tiene sentido tratar de contribuir a profundizar y ampliar esta línea de investigación extendiéndola a otras posibles concepciones simplistas sobre la ciencia y el trabajo científico (Gil 1993; Gil, Fernández y Carrascosa 1999).

Por otra parte, hemos concebido también $-\mathrm{y}$ en eso hemos encontrado escasos precedentes - que el lenguaje del cómic puede resultar un instrumento idóneo para ayudar a construir una imagen más correcta de la ciencia, susceptible de generar actitudes más positivas en los estudiantes y de contribuir, en definitiva, a una mejor alfabetización científico-tecnológica de los futuros ciudadanos y ciudadanas.

De acuerdo con ello, nos proponemos estudiar la posibilidad de utilizar el lenguaje del cómic como un instrumento especialmente indicado para, en primer lugar, detectar la existencia de concepciones simplistas respecto de la ciencia y del trabajo científico en general, así como para medir su grado de incidencia, y en segundo lugar, para cuestionar estas concepciones de la ciencia que adquieren los estudiantes y en última instancia, la imagen socialmente aceptada de la ciencia.

En este primer trabajo nos centraremos en el análisis crítico de la imagen de la ciencia transmitida por los cómics.

\section{HIPOTESIS QUE FOCALIZA LA INVESTIGACIÓN}


A tenor de lo expuesto hasta aquí y teniendo en cuenta, en particular, el propósito enunciado para este estudio, nuestra hipótesis básica supone que la imagen de la ciencia que proporcionan los cómics reflejará la misma imagen socialmente aceptada que se expresa mediante cualquier otro lenguaje. Una imagen que, insistimos, no se reduciría simplemente a atribuir la esencia de la actividad científica a la experimentación, sino que incluiría otros simplismos y deformaciones como, por ejemplo, la idea del científico "aislado del mundo", etc. (Gil, Fernández y Carrascosa 1999)y que los cómics reflejarían con especial claridad.

De este modo, dicha primera hipótesis podría reformularse más precisamente del siguiente modo:

Cabe esperar que en los cómics existentes en el mercado (en la medida que hagan referencia a un tema científico) así como los que podamos pedir que confeccionen nuestros alumnos o incluso los mismos profesores, se reflejen —por acción u omisióntoda una serie de concepciones simplistas acerca de la ciencia y del trabajo científico, tales como las que se indican a continuación:

Imagen empirista y ateórica. Se resalta el papel de la observación y de la experimentación "neutras" (no contaminadas por ideas apriorísticas), e incluso del puro azar, olvidando el papel esencial de las hipótesis y de la construcción de cuerpos globales y coherentes de conocimiento.

- Imagen rígida (algorítmica, exacta, infalible...). Se presenta el "método científico" como un conjunto de etapas a seguir mecánicamente. Se resalta, por otra parte todo lo que supone tratamiento cualitativo, control riguroso, etc., olvidando -o incluso rechazandotodo lo que significa invención o creatividad.

- Imagen aproblemática y ahistórica (ergo dogmática y cerrada). Se transmiten los conocimientos ya elaborados, sin mostrar cuáles fueron los problemas que generaron su construcción cuál ha sido su evolución, las dificultades, etc., ni mucho menos aún, las limitaciones del conocimiento científico actual o las perspectivas abiertas.

- Imagen exclusivamente analítica. Se resalta la necesaria parcelación de los estudios, su carácter acotado, simplificatorio, pero se olvidan los esfuerzos posteriores de unificación y de construcción de cuerpos coherentes de conocimiento cada vez más amplios, de tratamiento de problemas "puente" entre distintos campos que pueden llegar a unirse, etc.

- Imagen acumulativa y lineal. Los conocimientos aparecen como fruto de un crecimiento lineal, ignorando las crisis, las remodelaciones más o menos profundas de los cuerpos de conocimientos científicos, los periodos de estancamiento, etc.

- Imagen individualista: Los conocimientos científicos aparecen como obra de individuos aislados, ignorándose el papel del trabajo colectivo del intercambio entre equipos... En particular se deja creer que los resultados obtenidos por un sólo científico o equipo, pueden bastar para verificar o falsar una hipótesis o, incluso, toda una teoría.

Esta imagen individualista se presenta, a menudo, asociada con concepciones elitistas: 
- Imagen "velada" y elitista. Se presenta el trabajo científico como un dominio reservado a minorías especialmente dotadas, transmitiendo expectativas negativas hacia la mayoría de los alumnos, con claras discriminaciones de naturaleza social y de género (la ciencia es presentada como una actividad eminentemente "masculina"). Se contribuye a este elitismo escondiendo la significación de los conocimientos tras la complejidad del aparato matemático. No se hace un esfuerzo por hacer la ciencia más accesible (comenzando con tratamientos cualitativos, significativos), ni por mostrar su carácter de construcción humana, en la que no faltan confusiones ni errores... como los de los propios alumnos.

- Imagen descontextualizada, socialmente neutra. Se olvidan las complejas relaciones entre ciencia, tecnología y sociedad (CTS) y se proporciona una imagen de los científicos como seres "por encima del bien y del mal", encerrados en "torres de marfil" y ajenos a las necesarias tomas de decisión. Cuando estas relaciones son tenidas en cuenta se suele caer en planteamientos extremos muy simplistas: exaltación de la ciencia como factor absoluto de progreso o rechazo sistemático de la misma como algo condenable, intrínsecamente perverso, fuente de muchos de los graves problemas que aquejan a la humanidad, etc.

Conviene resaltar que, como se habrá podido constatar, nuestra hipótesis va más allá de la ya tradicional crítica al carácter empirista de la imagen de la ciencia transmitida por la enseñanza y dirige su atención hacia otras deformaciones a las que la crítica epistemológica ha prestado menos atención pero que, pensamos, pueden estar relacionadas y apoyarse mutuamente (Gil, Fernández y Carrascosa 1999).

En efecto, parece razonable, por ejemplo, que una imagen individualista y elitista de la ciencia apoye la idea empirista de "descubrimiento" y contribuya, además, a una lectura descontextualizada, socialmente neutra, de la actividad científica. Del mismo modo, por citar otro ejemplo, una imagen rígida, algorítmica, exacta, de la ciencia, puede reforzar una interpretación acumulativa, lineal, del desarrollo científico, ignorando las crisis y las revoluciones científicas.

En resumen pues, nuestra hipótesis supone que los alumnos comparten con los ciudadanos en general, un conjunto de imágenes deformadas de la ciencia y del trabajo científico, que se apoyan mutuamente entre sí y que son transmitidas en parte por los medios de comunicación y muy en particular, por los cómics.

\section{DISEÑOS EXPERIMENTALES}

Para determinar la imagen de la ciencia que transmiten los cómics hemos realizado un análisis de los mismos, dividiéndolos en dos grupos. En primer lugar, los cómics editados con fines recreativos (buscando aquellos que entre sus típicas historias hagan referencia a situaciones relacionadas de alguna manera con el trabajo científico); en segundo lugar, los cómics editados con fines educativos en torno a la enseñanza de la ciencia. Para contrastar nuestra hipótesis, se procedió a la elaboración de dos redes con las que analizar ambos grupos de cómics. Los ítems que conforman las redes están enfocados a detectar cualquier incidencia

-directa o indirecta- en las visiones deformadas de la ciencia y del trabajo científico. 
Antes de presentar las dos redes de análisis nos referiremos brevemente a los criterios con que fueron diseñadas. La hipótesis manejada, recordemos, indica que los cómics -incluso aquellos elaborados con fines educativos- pueden contribuir, por acción $u$ omisión, a afianzar una imagen "folk", distorsionada, de la ciencia. La cuestión, pues, no es sólo saber si se incide directamente en alguna deformación (como ocurre, por ejemplo, cuando se representa a un único científico como autor de avances prodigiosos). Se trata de ver, también, si esos cómics - $-\mathrm{y}$, muyen particular, los preparados con una finalidad educativa- combaten, o no, otras deformaciones que pueden formar parte de la visión distorsionada de la ciencia que poseen ya los estudiantes, como la idea de una ciencia "neutra", elaborada en "torres de marfil", ajena a los problemas de la sociedad, etc.

De este modo, las consecuencias operativas de la hipótesis se precisan y enriquecen, puesto que se añade a la existencia de ciertas deformaciones explícitas, la falta de acciones contra otras deformaciones que pueden quedar, así, inalteradas. Dicho de otra forma: se podría contribuir a una visión acumulativa, de crecimiento lineal del conocimiento científico, afirmando explícitamente que la ciencia avanza de forma regular, sin crisis ni retrocesos, pero ello es raro que se produzca. Más probable es que se contribuya indirectamente a dicha concepción a través de narraciones en las que no se contemplan esas posibles crisis, cambios profundos, etc. De acuerdo con ello, el diseño experimental ha de permitir contrastar ambas cosas: la incidencia directa y la falta de atención. Ha de ser posible de ese modo, al analizar un cómic, señalar en qué visiones deformadas incurre explícitamente y también cuáles ignora 0 , dicho con otras palabras, en cuáles incurre por omisión.

Para el caso de los cómics recreativos, claro esta, no puede esperarse un tratamiento cuidadoso de la naturaleza de la ciencia. Su contribución sólo puede ser indirecta y limitarse a algunos aspectos parciales, aunque sin duda relevantes. No tiene sentido pedir de un cómic, que se edita con fines recreativos, que dedique algún esfuerzo para salir al paso de una visión exclusivamente analítica de la ciencia. En efecto, en estos cómics se presentan historias sobre temas específicos y no cabe esperar que en ellos se trate de mostrar las relaciones existentes entre distintos dominios científicos. Análogamente, tampoco es de esperar que en estos relatos se intente cuestionar una visión acumulativa y lineal del desarrollo científico, que omite la existencia de algunos replanteamientos profundos y crisis en el mismo. Hemos optado, pues, por no incluir estas dos deformaciones en la red de análisis. Por el contrario, sí cabe temer que estos cómics recreativos incidan en, por ejemplo, el reduccionismo experimentalista típico de una imagen empirista y ateórica, es decir, en la idea de que la ciencia es fruto de la observación y de la experimentación, del "descubrimiento", (con olvido del papel jugado por el cuerpo de conocimientos, etc.). No se trata de esperar, claro está, que un cómic en el que, más o menos incidentalmente aparecen científicos trabajando, se proceda a resaltar el papel del cuerpo de conocimientos, pero si, al menos, de que la actividad científica no aparezca como algo pura y exclusivamente experimental.

Tampoco cabe esperar de estos cómics recreativos una postura beligerante contra las visiones deformadas de la ciencia. No tiene sentido, pues, hablar de que un cómic recreativo "combate" una determinada deformación o de que "incurre por omisión" en otra. Para cada deformación podremos decir, simplemente, que "se incide", "no se incide" o "no se trata". La tabla 1 (ver página siguiente) muestra la red de análisis elaborada para los cómics recreativos. 
Para el caso de los cómics educativos, por el contrario, cabe ser más exigentes, dada la finalidad con la que han sido diseñados. En efecto, los autores de los textos suelen ser científicos y profesores de ciencias que pretenden desarrollar una labor educativa utilizando el cómic como recurso estimulante y facilitador. Sin embargo, nuestra hipótesis es que la visión de la ciencia y de la actividad científica que los cómics (educativos) suelen ofrecer explícitamente se verá afectada por las deformaciones y reduccionismos a los que nos hemos venido refiriendo, que caracterizan a la imagen socialmente aceptada de la ciencia.

En general los criterios de evaluación adoptados han sido similares a los utilizados para los cómics recreativos, pero refiriéndonos ahora a "se incide explícitamente" (cuando el cómic incurre claramente en la deformación), "se combate" (si se muestra algo que vaya en contra de la deformación) y" se incide por omisión" (cuando no haya referencias ni a favor ni en contra de la misma). La tabla 2 (ver página siguiente), recoge la red de análisis propuesta.

Como puede constatarse, las principales diferencias entre esta red de análisis y la anterior, estriban en la inclusión de dos ítems más y una valoración más negativa de los aspectos no tratados. En efecto, si para el caso de un cómic recreativo era legitimo no criticar más que las deformaciones en las que se incurría explícitamente, ahora las ausencias merecen una valoración negativa, dada la finalidad educativa de estos cómics, puesto que no combatir una deformación supone favorecer su mantenimiento. Por ello consideramos que "se incide por omisión" en vez de, simplemente, "no se trata", como hacíamos en el primer caso.

Tabla 1. Red de análisis para determinar la imagen de la ciencia que transmiten los cómics recreativos.

\begin{tabular}{|c|c|c|c|}
\hline Visiones deformadas & $\begin{array}{c}\text { Se } \\
\text { incide }\end{array}$ & $\begin{array}{l}\text { No se } \\
\text { incide }\end{array}$ & $\begin{array}{l}\text { No se } \\
\text { trata }\end{array}$ \\
\hline $\begin{array}{l}\text { 1. Empirista y ateórica. Se resalta exclusivamente el papel de } \\
\text { la observación y de la experimentación. La actividad } \\
\text { científica está relacionada con el azar, o es fruto de } \\
\text { observaciones desligadas de cualquier planteamiento } \\
\text { teórico. (Es suficiente, la aparición de algún libro para que } \\
\text { digamos que no se incide en esta deformación). }\end{array}$ & & & \\
\hline $\begin{array}{l}\text { 2. Rígida (algorítmica, exacta. .1. Se presenta el "método } \\
\text { científico" como una receta en un orden prefijado. (Bastará } \\
\text { con que se incluya alguna remodelación para considerar que } \\
\text { no se incide). }\end{array}$ & & & \\
\hline $\begin{array}{l}\text { 3. Aproblemática (ergo dogmática y cerrada): Se transmiten } \\
\text { conocimientos ya elaborados, sin mostrar cuales fueron los } \\
\text { problemas que generaron su construcción, ni cuál ha sido su } \\
\text { evolución, las dificultades, etc. (Diremos que no se incurre } \\
\text { en esta deformación cuando, p.e., aparezcan los objetivos } \\
\text { de una investigación). }\end{array}$ & & & \\
\hline $\begin{array}{l}\text { 4. Individualista. La actividad científica aparece como fruto de } \\
\text { individuos aislados, ignorándose el papel del trabajo }\end{array}$ & & & \\
\hline
\end{tabular}




\begin{tabular}{|l|l|l|}
\hline colectivo, de los intercambios entre equipos... (Bastará con & & \\
que salgan varias personas para admitir que no se transmite \\
esta imagen).
\end{tabular}

Tabla 2. Red de análisis para determinar la imagen de la ciencia que transmiten los cómics educativos.

\begin{tabular}{|c|c|c|c|}
\hline Visiones deformadas & $\begin{array}{c}\text { Se incide } \\
\text { explícita- } \\
\text { mente }\end{array}$ & $\begin{array}{l}\text { Se incide } \\
\text { por } \\
\text { omision }\end{array}$ & $\begin{array}{c}\text { Se } \\
\text { combate }\end{array}$ \\
\hline $\begin{array}{l}\text { 1. Empirista y ateórica. Se incurre en esta visión } \\
\text { cuando se representan laboratorios en donde } \\
\text { sólo aparecen instrumentos, cuando se asocia el } \\
\text { comienzo de una investigación a simples } \\
\text { observaciones casuales, etc. (Bastará con la } \\
\text { inclusión de libros o revistas para que digamos } \\
\text { que se combate. }\end{array}$ & & & \\
\hline $\begin{array}{l}\text { 2. Rígida (algorítmica exacta....). Se presenta el } \\
\text { "método científico" como un conjunto ordenado } \\
\text { de etapas a seguir mecánicamente. (Bastará con } \\
\text { que se haga referencia a algún replanteamiento } \\
\text { del problema, concepción de nuevas hipótesis, } \\
\text { etc., para que digamos que se combate.). }\end{array}$ & & & \\
\hline $\begin{array}{l}\text { 3. Aproblemática y ahistórica (ergo dogmática y } \\
\text { cerrada). Se transmiten conocimientos ya } \\
\text { elaborados, sin mostrar cuales fueron los } \\
\text { problemas que generaron su construcción, cuál } \\
\text { ha sido su evolución, las dificultades, etc., ni } \\
\text { mucho menos aún, las limitaciones del }\end{array}$ & & & \\
\hline
\end{tabular}




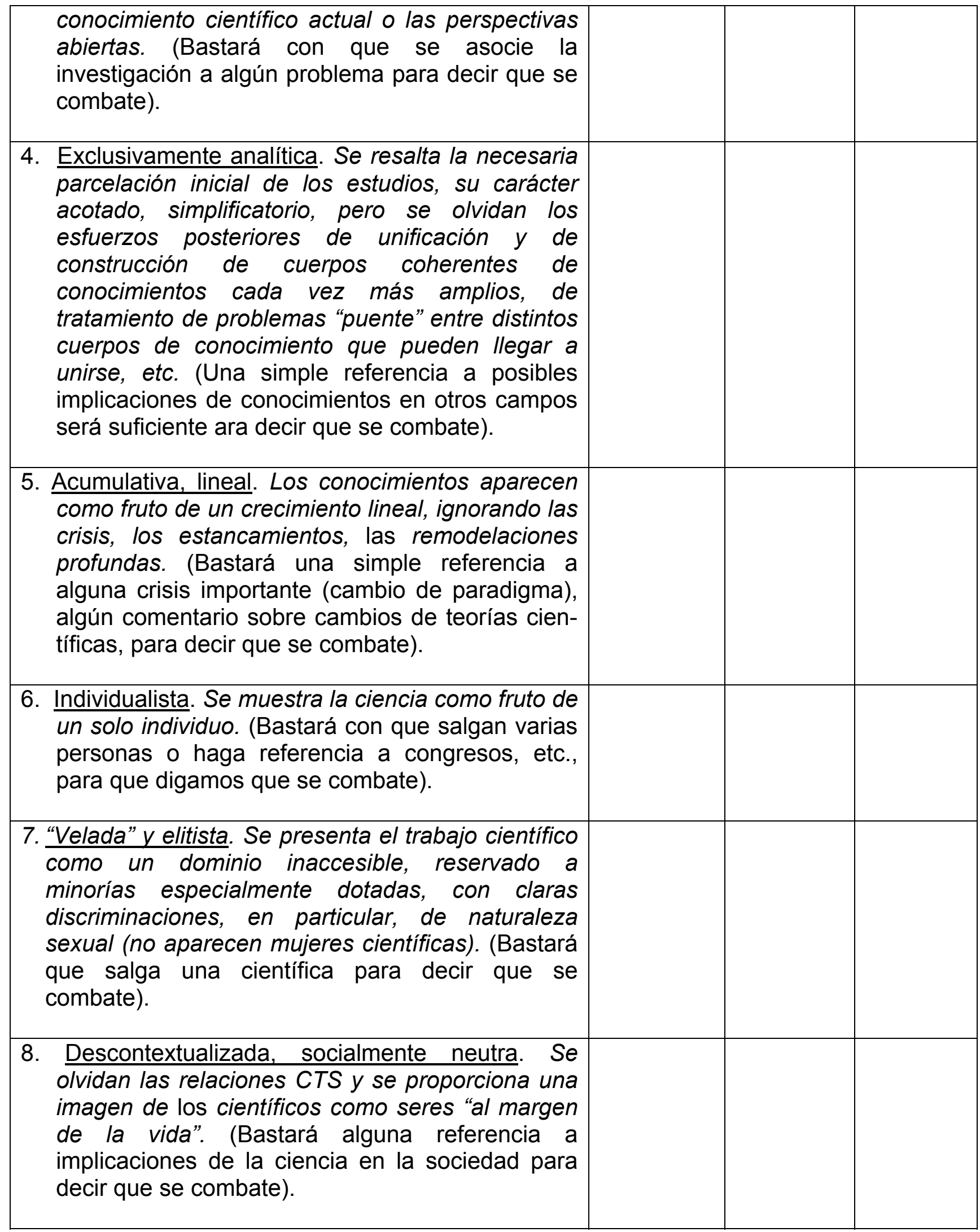

\section{RESULTADOS OBTENIDOS}


Antes de hablar de resultados cuantitativos y para facilitar la comprensión de los ítems y de los criterios utilizados para determinar la imagen de la ciencia que transmiten los cómics, vamos a recurrir a analizar, a título de ejemplo, un cómic recreativo y un cómic educativo.

\subsection{Análisis, a título de ejemplo ilustrativo, de un cómic recreativo}

En la figura 1 reproducimos el cómic "El descubrimiento definitivo". (Por razones de espacio nos hemos limitado a incluir cuatro viñetas suficientemente significativas).
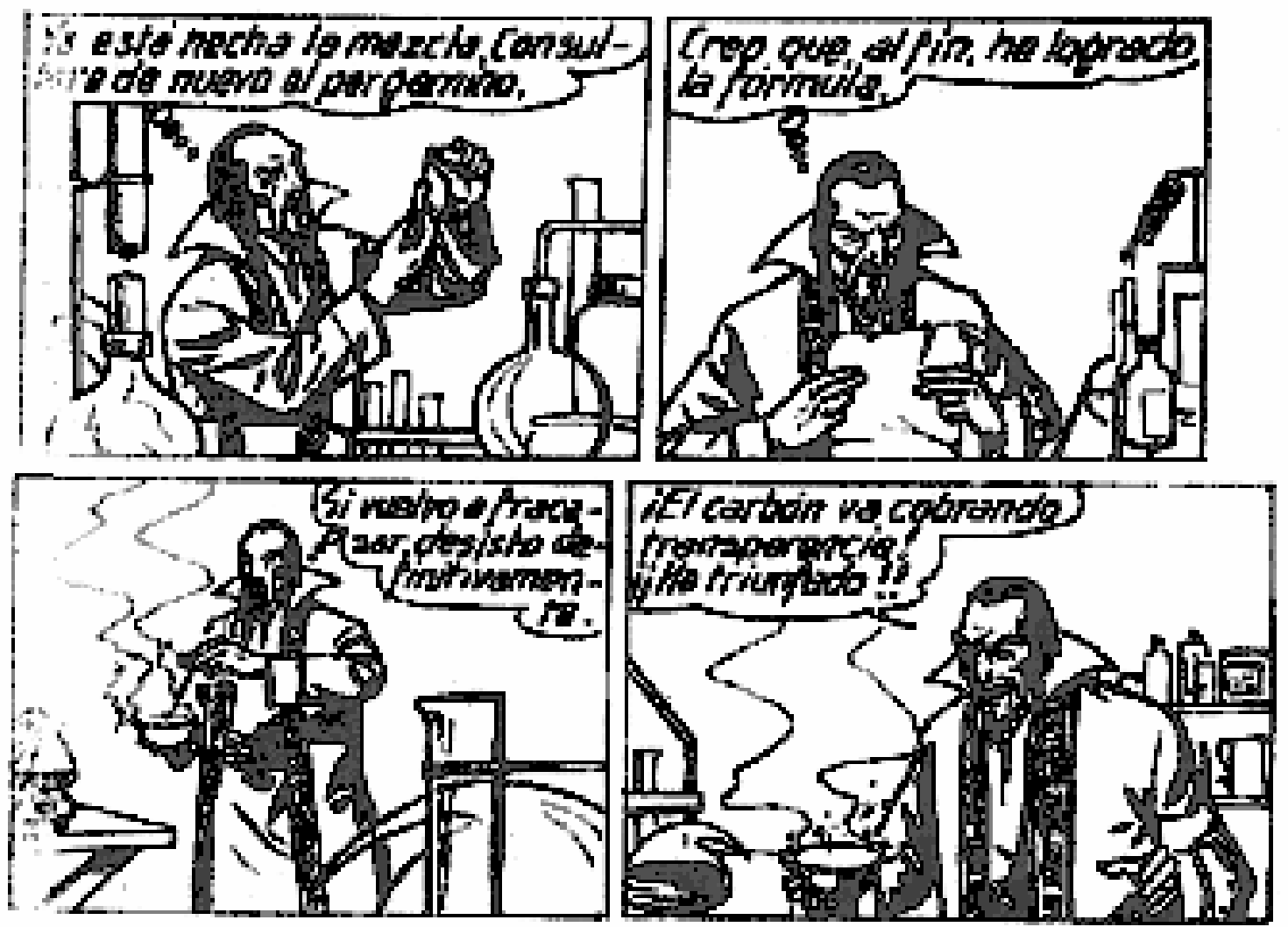

Figura 1. Tortajada et al, 1994, El descubrimiento definitivo, Roberto Alcazar. Editorial Valenciana

Al aplicar los seis ítems elaborados (tabla 1) al cómic de la figura 1, de acuerdo con los criterios expuestos anteriormente, hemos considerado que en dicho cómic se incide en cuatro de las deformaciones contempladas en la red de análisis, por las razones que se exponen brevemente a continuación:

- Imagen empirista y ateórica; solo se dibujan instrumentos, ni siquiera aparecen libros, revistas u otras fuentes de consulta bibliográfica.

- Imagen individualista; solo aparece una persona.

- Imagen elitista; se muestra el estereotipo del científico, hombre, con bata blanca, encerrado en un laboratorio...

- Imagen descontextualizada; se muestra un laboratorio aislado sin referencia alguna a posibles relaciones ciencia - técnica - sociedad. 
No hemos considerado que incurre, en cambio, en estas otras deformaciones:

- Imagen rígida; el simple hecho de referirse numerosos intentos, a posibilidad de un nuevo fracaso, etc., basta para que aceptemos que no se incurre en esta deformación (pese a que la expresión consultaré de nuevo el pergamino" parece hacer referencia a una receta).

- Imagen aproblemática; aunque aquí no hemos representado la totalidad del cómic se intuye claramente que el personaje va detrás de una determinada pócima y que su trabajo tiene, pues, una finalidad definida.

Como se habrá constatado, adoptamos en cada caso el criterio más desfavorable para nuestra hipótesis, con objeto de que los resultados obtenidos merezcan el mayor crédito.

\subsection{Análisis, a título de ejemplo ilustrativo, de un cómic educativo}

En la figura 2 reproducimos un cómic educativo-tomado de un reciente trabajo de la revista Educación en Ciencias (Yonni et al, 1 997)— sobre la obra de Roger Bacon, que pasaremos a analizar con los ítems de la tabla 2.

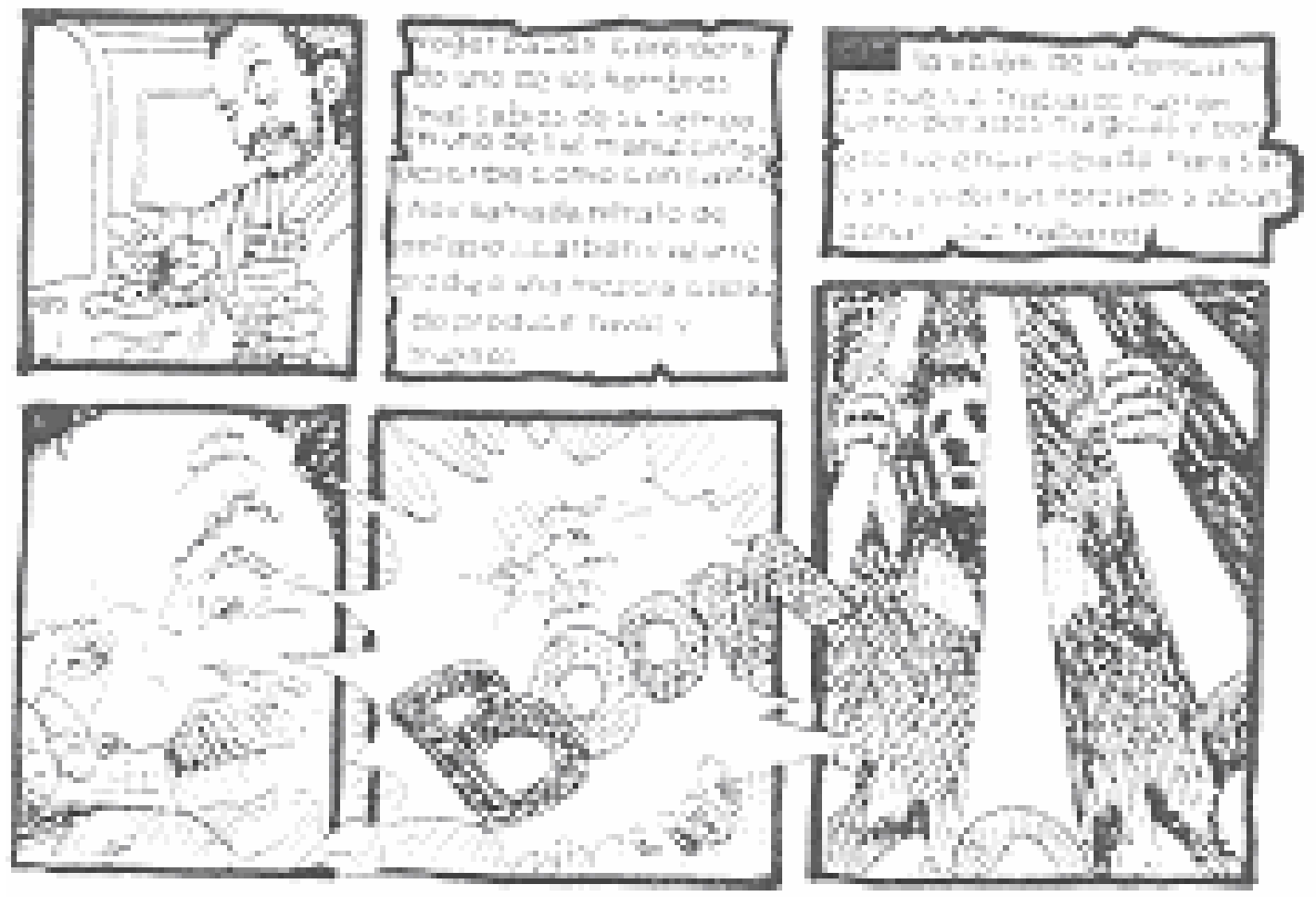

Figura 2. Los alquimistas (Roger Bacon). (Yonni et al., 1997),

El análisis realizado permite concluir que en el cómic se incide en las siguientes deformaciones, por las razones que se indican en cada caso:

- Imagen empirista y ateórica; sólo se incluyen instrumentos y escenas de manipulación, sin que aparezca siquiera un libro que permita pensar en una consulta bibliográfica, etc. 
- Imagen aproblemática y ahistórica; no se hace referencia el problema del que parte la investigación.

- Imagen individualista; aparece un solo investigador.

- Imagen velada y elitista; imagen tópica del científico genial ("uno de los hombres más sabios").

Por otra parte, consideramos que en el cómic no se cuestionan (se incide por omisión) las siguientes concepciones:

- Imagen rígida; no se hace referencia a ensayos, rectificaciones, búsqueda de nuevos caminos...

- Imagen exclusivamente analítica. Se aborda una cuestión aparentemente puntual, sin hacer referencia a posibles implicaciones de conocimientos, vinculación de distintas áreas.

- Imagen acumulativa, decrecimiento lineal; no se dice nada que apoye o cuestione la idea de una ciencia que se desarrolla por simple acumulación de conocimientos, sin crisis ni remodelaciones profundas.

Por último, consideramos que en el cómic no se incide en la imagen descontextualizada, ya que aparece la influencia de la sociedad sobre la ciencia.

Utilizando criterios como los que acabamos de ilustrar hemos procedido a analizar 40 cómics recreativos y 40 cómics educativos. En los apartados 4.3 y 4.4 presentamos los resultados correspondientes.

\subsection{Resultados correspondientes a la imagen de la ciencia que transmiten los cómics recreativos}

La tabla 3 recoge los resultados correspondientes al análisis de los cómics recreativos.

Tabla 3. Datos globales del análisis de los cómics editados con fines recreativos $(N=40)$.

\begin{tabular}{|c|c|c|c|c|c|c|}
\hline Visiones simplistas & \multicolumn{2}{|c|}{$\begin{array}{l}\text { Se incide } \\
\text { (\%) (s.d.) }\end{array}$} & \multicolumn{2}{|c|}{$\begin{array}{l}\text { No se incide } \\
\text { (\%) (s.d.) }\end{array}$} & \multicolumn{2}{|c|}{$\begin{array}{l}\text { No se trata } \\
\text { (\%) (s.d.) }\end{array}$} \\
\hline 1.Empirista y ateórica & 45 & $(7.8)$ & 20 & $(6.3)$ & 35 & $(7.5)$ \\
\hline 2.Rígida & 20 & $(6.3)$ & 5 & $(2.7)$ & 75 & $(6.8)$ \\
\hline 3.Aproblemática y ahistórica & 2.5 & (2.4) & 42.5 & $(7.8)$ & 55 & (7.9) \\
\hline 4.Individualista & 65 & $(7.5)$ & 32.5 & $(7.4)$ & 2.5 & $(2.4)$ \\
\hline 5.Elitista & 85 & $(5.6)$ & 12.5 & $(5.5)$ & 2.5 & $(2.4)$ \\
\hline 6.Descontextualizada & 15 & $(5.6)$ & 40 & $(7.7)$ & 45 & (7.8) \\
\hline
\end{tabular}

Un análisis detenido, siguiendo los criterios expuestos anteriormente nos permite concluir que los cómics recreativos presentan las siguientes deformaciones de la actividad científica:

- Transmiten imágenes empiristas y ateóricas, pues en el $45 \%$ de los casos se resalta exclusivamente la observación y la experimentación y no se hace referencia al cuerpo teórico de conocimientos como punto de partida en un ciclo de investigación (ni siquiera se incluye la presencia de un libro). Los hallazgos aparecen como fruto del azar o como el 
resultado de reiterados ensayos. Tan sólo en el $20 \%$ de estos cómics aparecen imágenes que permiten cuestionar este experimentalismo simplista.

- La mayoría de los cómics recreativos (el 75\%) no dicen apenas nada del proceso seguido para realizar un "descubrimiento". Cuando se muestra dicho proceso, se incurre, en general, en una visión rígida del "método científico", que aparece como una mera receta.

- Por el contrario, los cómics recreativos suelen incurrir menos en una visión aproblemática, dado que en un porcentaje significativo (42.5\%), las "investigaciones" tienen una finalidad clara, un problema a resolver que constituye, como es lógico, un elemento esencial de la aventura narrada.

- La deformación individualista aparece, en cambio, con nitidez: en el $65 \%$ de los casos, el trabajo científico aparece realizado por una sola persona.

- Lo mismo ocurre con la visión elitista, en la que incide el $85 \%$ de los cómics recreativos, que responden al estereotipo del científico varón, en general calvo y con gafas, vestido de bata blanca, etc.

- No se puede decir, por último, que estos cómics incurran en una visión descontextualizada de la actividad científica (sólo en un $15 \%$ esa actividad se muestra sin relación alguna con la sociedad). Pero en el $40 \%$ de los que hacen referencia a las relaciones CTS se transmite una imagen muy simplista, con científicos empeñados en dominar la humanidad con "armas invencibles", etc.

Podemos concluir, pues, que los cómics recreativos proporcionan una imagen deformada y empobrecida de la actividad científica, tal como habíamos conjeturado.

\subsection{Resultados correspondientes a la imagen de la ciencia en los cómics educativos}

Los resultados que a continuación se muestran (tabla 4) fueron obtenidos tras aplicar la correspondiente red de análisis (tabla 2) a 40 cómics editados con fines educativos.

Comentaremos brevemente dichos resultados:

- Como vemos, el $52.5 \%$ de los cómics educativos analizados presentan visiones empiristas y ateóricas, resaltando exclusivamente la observación y la experimentación. Los descubrimientos aparecen como resultado de experimentos cruciales, capaces de suministrar a las leyes de la naturaleza la validez absoluta de hechos probados.

- En el $97.5 \%$ de estos cómics no se dice nada que pueda combatir la idea de "método científico", considerado como una suma de pasos a seguir mecánicamente para obtener los conocimientos y con frecuencia se deja pensar que el "método" se reduce a observación, experimentación y análisis de resultados.

- Un $32.5 \%$ de los cómics educativos incurren explícitamente en visiones aproblemáticas y ahistóricas y otro $27.5 \%$ lo hacen por omisión, con lo que un total del $60 \%$ incurren en esta deformación, sin intentar relacionar los conocimientos con los problemas que están en su origen ni tampoco presentar su evolución. 
- De forma similar, un $77.5 \%$ de los cómics educativos analizados no incluyen ningún elemento que permita combatir la imagen exclusivamente analítica de la ciencia, a la que se une otro $10 \%$ que incide directamente en dicha deformación.

- En el caso de una visión de crecimiento puramente acumulativo del conocimiento científico, los cómics educativos inciden explícitamente en un $32.5 \%$ y otro $52.5 \%$ lo hace por omisión.

- También las imágenes individualista y elitista están ampliamente extendidas, con, respectivamente, una incidencia directa del $77.5 \%$ y del $85 \%$. Sólo en un $15 \%$ se representa a más de un investigador. Y sólo en el $10 \%$ de los cómics se incluye a alguna científica.

- En un $35 \%$ de los casos, por último, se incide explícitamente en visiones descontextualizadas, mostrando a los científicos como seres aislados de la sociedad.

Tabla 4. Datos globales del análisis de los cómics editados con fines educativos $(N=40)$.

\begin{tabular}{|c|c|c|c|}
\hline ITEMS & $\begin{array}{l}\text { Se incide } \\
\text { explí- } \\
\text { citamente } \\
\text { (\%) } \quad \text { (s.d.) }\end{array}$ & $\begin{array}{l}\text { Se incide } \\
\text { por } \\
\text { omisión } \\
\text { (\%) (s.d.) }\end{array}$ & $\begin{array}{c}\text { Se } \\
\text { combate } \\
(\%) \quad \text { (s.d.) }\end{array}$ \\
\hline 1.Imagen empirista y ateórica & $52.5(7.9)$ & $32.5(7.4)$ & $(5.6)$ \\
\hline 2.Imagen rígida & $(2.4)$ & $97.5 \quad(2.4)$ & 0 \\
\hline 3.Imagen aproblemática y ahistórica & $32.5 \quad(7.4)$ & $27.5 \quad(7.6)$ & $(7.7)$ \\
\hline 4.Imagen exclusivamente analítica & $(4.7)$ & $77.5 \quad(6.6)$ & $12.5 \quad(5.2)$ \\
\hline 5.Imagen acumulativa, de crecimiento lineal & $32.5 \quad(7.4)$ & $52.5 \quad(7.4)$ & $(5.6)$ \\
\hline 6.Imagen individualista & $77.5 \quad(6.6)$ & $(4.1)$ & $(5.6)$ \\
\hline 7.Imagen elitista & $(5.6)$ & $(3.4)$ & $(4.7)$ \\
\hline 8.Imagen descontextualizada & $(7.5)$ & $(3.4)$ & $(7.7)$ \\
\hline
\end{tabular}

\section{CONCLUSIONES PROVISIONALES Y PERSPECTIVAS}

El trabajo realizado hasta aquí nos ha permitido constatar la contribución de los cómics, incluidos aquellos elaborados con finalidades educativas, a una imagen deformada y empobrecida de la ciencia, lo que refuerza la idea de que se trata de una imagen "folk" de la ciencia, socialmente aceptada, que cabe esperar encontrar también en los estudiantes. Actualmente estamos investigando, precisamente, la utilización de los cómics para poner en evidencia las concepciones de los estudiantes así como para lograr su transformación.

Los primeros y prometedores resultados parecen indicar que las concepciones deformadas de los estudiantes sobre la ciencia constituyen un serio obstáculo... tan sólo en la medida en que no se favorece un mínimo análisis crítico de las mismas, como el que intentamos propiciar utilizando, entre otros, el lenguaje del cómic. 
BASSALLA, G., 1976. Pop Science: the depiction of science in popular culture. En, G Holton \& w. Blanpied (Ed), Science and its public, (Dordrecht, Holland: D Reidel). 261278.

BELL, B. F. Y PEARSON, J., 1992. Better learning, International Journal of Science Education, 14(3), 997- 1001.

CHAMBERS, W. D, 1983. Stereotypic images of the scientists: The Draw - A- Scientists Test, Science Education, 67(2), 255 - 265.

DÉSAUTEL,J., LAROCHE,M., GAGNĖ,B.,Y RUEL, F., 1993. La formation a l'enseignement des sciences: le virage épistémologique, Didaskalia, 1, 49- 67.

GIL, D., 1993. Contribución de la historia y de la filosofía de las ciencias al desarrollo de un modelo de enseñanza aprendizaje como investigación, Enseñanza de las Ciencias, 11(2), 197-212.

GIL D., FERNÁNDEZ I. y CARRASCOSA J., 1999. La transformación de las concepciones docentes espontáneas sobre la ciencia. En Carretero M. Libro pendiente de publicación.

GUILBERT, L, y MELOCHE, D., 1993. L'idée de science chez des enseignants en formation: Un lien entre I'historie des sciences et l'hétéreogéneité des visions? Didaskalia, 2, 7 - 30.

HODSON, D., 1993. Philosophic stance of secondary school science teachers, curriculum experiences and children's understanding of science: some preliminary finding, Enseñanza de las Ciencias, 12 (2), 281 - 282.

HODSON, D., 1994. Hacia un enfoque más critico del trabajo de laboratorio, Enseñanza de las Ciencias, 12(3), 299-313.

McADAM, J., 1990. The persistent stereotype: Children's images of scientists, Physics Education, 25, 102 - 105.

MEICHTRY, Y, 1993. The impact of science curricula on student views about the nature of science, Journal of Research in Science Teaching, 30(5), 429 - 443.

NATIONAL RESEARCH COUNCIL, 1996. National Science Standards, National Academy Press: Washington D.C.

PORLAN, R., Y MARTíN. R., 1994. El saber práctico de los profesores especialistas, aportaciones desde las didácticas especificas, Investigación en la Escuela, 24, 49-59

SCHIBECI, R., 1986. Images of science and scientists and science education, Science Education, 70 (2), 139 - 149.

SIMPSON, R., et al, 1994. Research on the affective dimension of science learning. En Gabel (Ed), 1994, Handbook on Science Teaching and Learning, (McMillan Pub co: N.Y.). 
YAGER, R., \& PENICK, J., 1983. Analysis of the current problems with school science in the USA, European Journal of Science Education, 5, 463 - 469.

YONNI F. , FASOLC H., BU DNIK L., 1997. La historieta como técnica auxiliar en la enseñanza de la ciencia, Educación en Ciencias, 1(2), 47-55. 